was eventually weaned from ventilator support but had a massive stroke at nearly 10 months.

\section{Conclusion}

The AbioCor replacement heart supported the circulation in a patient with end-stage biventricular heart failure with fixed pulmonary hypertension for 293 days. There were no device malfunctions. Physiologic flows permitted activities that exceeded the preoperative state for several months. Pulmonaryrelated complications developed in the immediate postoperative period and resolved. Respiratory failure redeveloped at 2 months and persisted. The unnatural history of fixed pulmonary hypertension in the setting of a total heart replacement system remains an entity of uncertainty. Further studies will be neces- sary to determine whether fixed pulmonary hypertension is an indication or contraindication to destination therapy with a total heart replacement system.

\section{References}

1. Cimato TR, Jessup M. Recipient selection in cardiac transplantation: contraindications and risk factors for mortality. J Heart Lung Transplant. 2002;21:1161-73. Review.

2. Dowling RD, Gray LA Jr, Etoch SW, Laks H, Marelli D, Samuels L, et al. The AbioCor implantable replacement heart. Ann Thorac Surg. 2003;75(6 Suppl):S93-9.

3. Samuels LE, Dowling R. Total artificial heart: destination therapy. Cardiol Clin. 2003;21:115-8.

4. Kukuy EL, Oz MC, Rose EA, Naka Y. Devices as destination therapy. Cardiol Clin. 2003;21:67-73.

\title{
Successful bilateral lung volume reduction in a child with emphysema from bronchiolitis obliterans
}

\author{
Maurizio Mancuso, MD, ${ }^{a}$ Donatella Pacchioni, MD, ${ }^{\mathrm{c}}$ Enrico Ruffini, MD, \\ Antonio Cavallo, MD, ${ }^{a}$ Pierluigi Filosso, MD, ${ }^{a}$ Aurelio Viale, MD, ${ }^{\mathrm{b}}$ Paolo Solidoro, MD, \\ and Elisabetta Bignamini, MD, ${ }^{\mathrm{e}}$ Torino, Italy
}

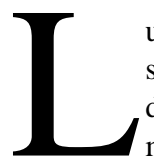
ung hyperinflation occurs not only because of emphysema but also because of small airways diseases with distal air trapping. In infancy bronchiolitis is quite common among airways diseases. We describe the case of a 9-year-old child with end-stage emphysema caused by bronchiolitis and associated chest wall deformity, who was excluded from lung transplantation as a result of severe osteoporosis and who underwent successful bilateral lung volume reduction (LVR) through a median sternotomy.

\section{Clinical Summary}

At the age of 18 months, because of dyspnea and pulmonary infiltrates, the infant underwent an open middle lobe biopsy with evidence of aspecific bronchiolitis obliterans. Furthermore, the patient had a chest wall abnormality consistent with pectus cari-

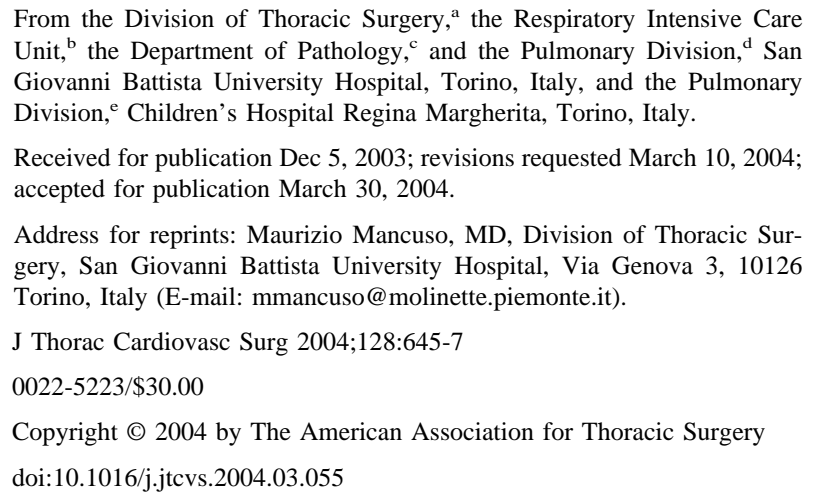

natum and kyphosis (Figure 1). Pulmonary function tests (PFTs) throughout childhood and chest radiographs were consistent with chronic ob-

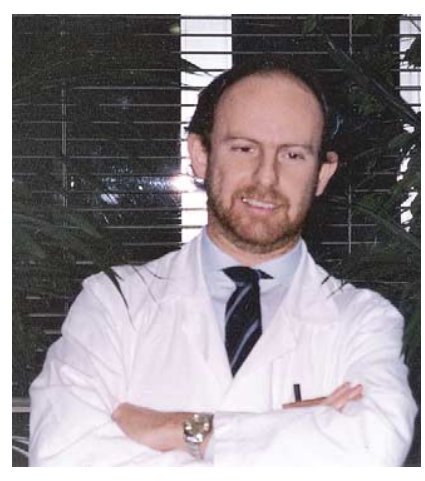

Dr Mancuso structive pulmonary disease. $\alpha 1$-Antytripsin levels and sweat test results were normal.

At the age of 7 years, he worsened, with severe exertional dyspnea necessitating frequent hospitalizations. Prednisone was augmented to $1 \mathrm{mg} / \mathrm{kg}$. The patient was referred to a lung transplantation program abroad because of his age. Meanwhile, his osteoporosis became symptomatic, with spontaneous fracture of the right clavicle, and the child was again referred to us. Recalcification therapy was then started, along with tapering of prednisone to $0.3 \mathrm{mg} / \mathrm{kg}$. The bone disease improved, but a further worsening of respiratory function occurred.

He quit going to school and was very disabled at home in New York Heart Association class III. Forced expiratory volume in 1 second $\left(\mathrm{FEV}_{1}\right)$ decreased to $26 \%$, total lung capacity (TLC) was $132 \%$, residual volume (RV) was $310 \%$, and RV/TLC was $226 \%$ of predicted value. The diffusing capacity of the lung for carbon monoxide was $75 \%$ of the normal values, $\mathrm{PaO}_{2}$ was $61 \mathrm{~mm} \mathrm{Hg}$, and $\mathrm{CO}_{2}$ was normal. During the 6-minute walking test, he walked $440 \mathrm{~m}$, and on the treadmill test, he completed the sixth level with $4 \mathrm{~L}$ of oxygen, with a dyspnea Borg index of 14. A high-resolution computed tomograph showed lung hyperinflation and luscency, a transmediastinal hernia of the right upper lobe, and medium-sized bullae in the left lower lobe.

A Q scan showed $62 \%$ perfusion on the right lung and $38 \%$ on the left. Very low nuclear uptake was observed in the left lower lobe $(6 \%)$ and in the right upper lobe $(13 \%)$. 


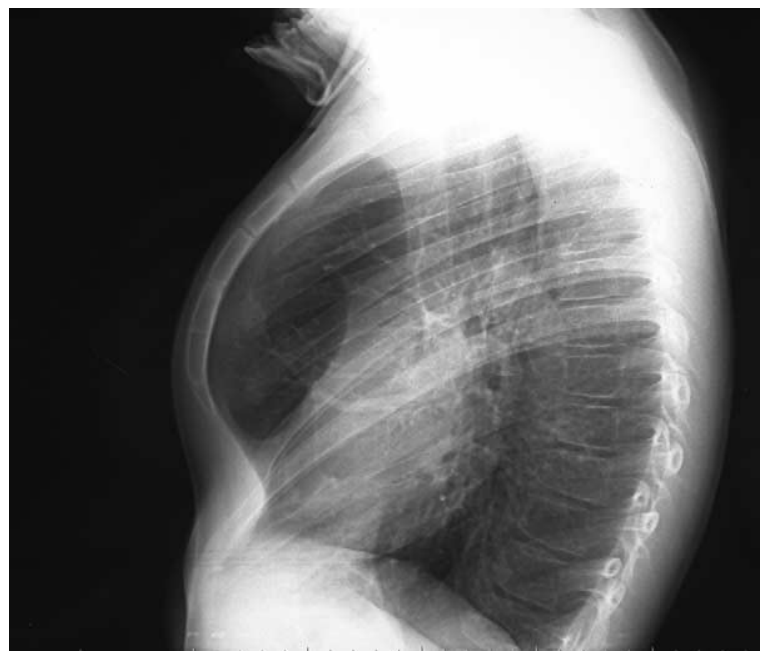

Figure 1. Chest wall deformity with pectus carinatum and kyphosis.

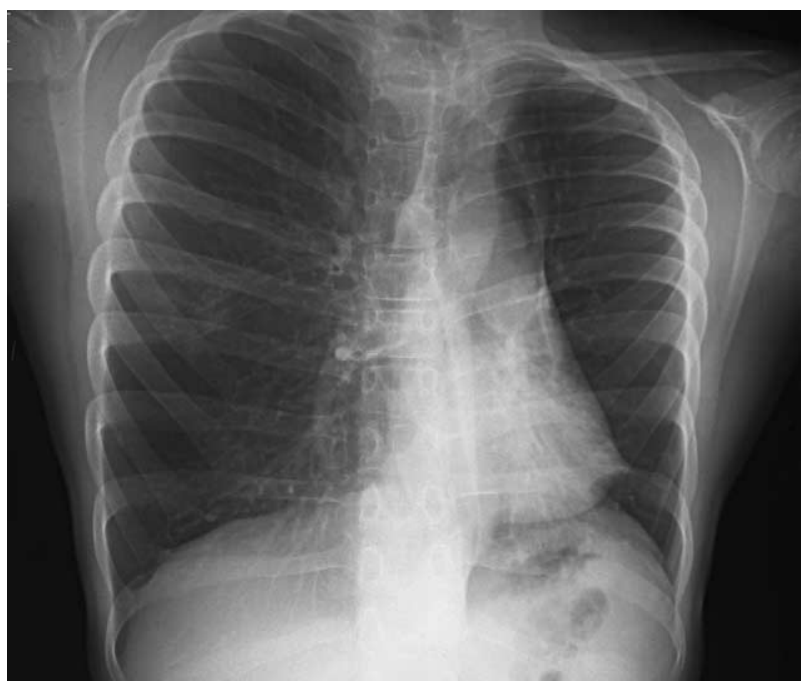

\section{Figure 2. Preoperative chest radiograph with severe hyperinflation.}

To delay the lung transplantation, we decided to perform a bilateral LVR through a median sternotomy on the basis of the severe hyperinflation and the presence of target areas.

First, on the left g. 27 of the bullous lower lobe leaving the upper segment intact on $\mathrm{g}$. 26 of the homogenously hyperinflated lingual were resected. On the right side, after dissection of the pleural adhesion from the previous thoracotomy, g. 50 of parenchyma with an inverted U-shaped resection on the upper lobe and a linear resection on the middle lobe were excised. The mediastinal pleura were closed on both sides without the need for pleural tents. Four chest tubes were placed through the subxiphoid area.

The patient was extubated in the room. On postoperative day (POD) 1, a relevant change of the chest shape was noted (Figures 2 and 3). The postoperative course was uneventful, and a pro-

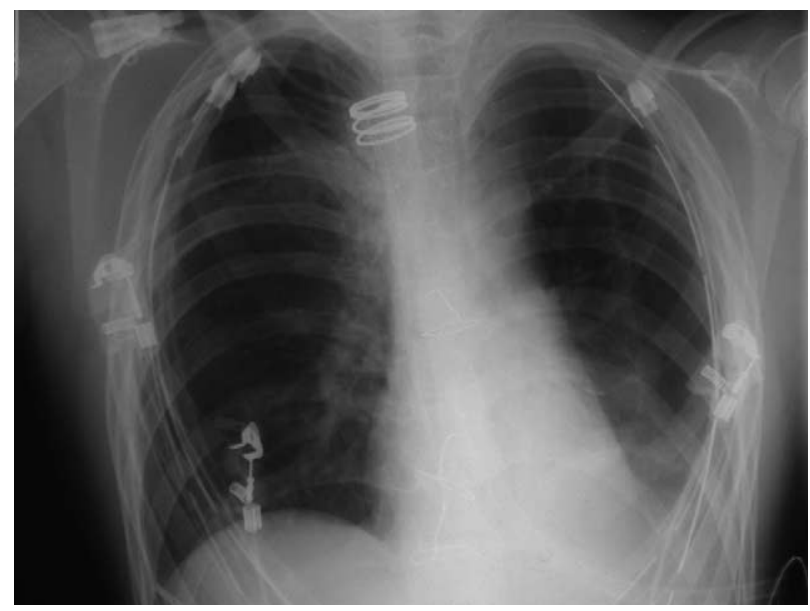

Figure 3. POD 1 chest radiograph with impressive change in the chest shape.

longed air leak was observed in only one of the right chest tubes, which was removed on POD 16 after 5 days on a Heimlich valve. The patient was discharged on POD 18 in very good condition. He told us that "now air gets in and out my chest."

The specimens were seen by our pathologists and revised by others abroad. The diagnosis was consistent with panacinar and focally also centrolobular emphysema, eosinophilic bronchitis, and bronchiolitis with mucus impaction and focal foam cell reaction developing into focal organizing pneumonia.

Because of the suspicion that an allergic bronchopulmonary mycosis of the mucoid impaction type was involved, a TC of the nasal and paranasal sinuses was redone. Diffuse sinusitis was found, as was hypertrophic tonsillitis.

After 3 months, the patient has an impressive relief of symptoms and is going to school. He is enrolled in a training program, and an ear, nose, and throat procedure for eradication of chronic infections is planned.

The PFTs at 3 months have shown up to now a light improvement of $\mathrm{FEV}_{1}$ up to $33 \%$ and a decrease of RV and TLC down to $110 \%$ and $240 \%$, respectively, of predicted values.

He was able to walk $540 \mathrm{~m}$ in 6 minutes and to reach the sixth level on the treadmill without supplementary oxygen, with an $\mathrm{HbO}_{2}$ saturation always greater than $93 \%$ and an evident reduction of the dyspnea Borg index down to 7. Also impressive was the improvement of $\mathrm{PaO}_{2}$ to $81 \mathrm{~mm} \mathrm{Hg}$.

The 6-month evaluation is underway, but the clinical impression is of further improvement.

\section{Discussion}

LVR has been shown to provide symptomatic benefits to patients affected with emphysema provided that anatomic and physiologic criteria are met. Before thoracic surgery, chest wall abnormalities and bronchitis or bronchiectasis are considered exclusion criteria.

We present this case because of the peculiarity of the age, the type of the disease causing the hyperinflation, and the existence of a chest wall abnormality.

LVR is anecdotal in infancy. In the literature we found only 3 reports, which were different for surgical technique and indica- 
tions. Messineo and colleagues ${ }^{1}$ in 2001 described a left lower lobectomy and a further LVR on the same left lung in a neonate affected with a severe unilateral pulmonary interstitial emphysema. Bloch and associates ${ }^{2}$ in 2002 reported a bilateral LVR (through 2-staged lateral thoracotomies) in a 14-year-old boy with hyperinflation caused by constrictive bronchiolitis. Finally, Cohen and coworkers ${ }^{3}$ in 2003 described the case of an 8-year-old boy who underwent left lower lobe lobectomy for severe emphysema caused by bronchiolitis obliterans.

The present case reports the first bilateral sequential LVR through a sternotomy in infancy with the technique described in adults by Cooper and Patterson. Neither the adhesions caused by the previous thoracotomy nor the abnormality of the chest wall were a technical concern.

Regarding the type of disease causing the hyperinflation, in most clinical series, the unique distinction found is between $\alpha 1$ antitrypsin deficiency emphysema and smoking emphysema. On the contrary, few articles address the pathology of the lung tissue resected during LVR surgery. ${ }^{4,5}$ A variety of unexpected findings were reported, and bronchiolitis was one of the more common. However, in our opinion this aspect is not conflicting with the assumption that centrolobular emphysema is very often caused by bronchiolitis.

However, our case is not consistent with these unexpected diagnoses. The onset of the disease was at the age of 1 year, with pulmonary infiltrates and a clinical pattern of an infective and inflammatory disease and symptomatic dependence on steroids. At 18 months of age, an open lung biopsy was performed, and the histologic diagnosis was of bronchiolitis. These biopsy results were recently reviewed. In addition, $\alpha 1$-antitrypsin results were negative, and smoking was obviously not in play.

If the relief of symptoms and the improvement of oxygenation are relevant, we have some concerns about the poor change in the PFTs. The FEV ${ }_{1}$ has improved only by $27 \%$, and the TLC and RV have decreased only by $20 \%$. However, we rely on an appropriate amount of parenchyma removed according to the size of the patient.

We hypothesize 2 explanations. The first is that the chest cage deformity is avoiding more complete elastic recoil, slowing down the expiratory flow. The anterior retrosternal dilation of the chest cavity is unlikely to be modified by the loss of lung volume or by the physiotherapy. In other words, if this is reasonable, the exclusion criteria regarding the chest wall abnormalities is binding. The second is that the already untreated ear, nose, and throat infections are maintaining the airways disease.

In conclusion, in selected cases hyperinflation as a result of causes other than the more common cause of emphysema is a good indication for LVR surgery. This procedure could be safely done in infancy bilaterally through a sternotomy. The interaction between the growth of the child, the progression of the hyperinflation, and the potential detrimental effect of chest wall deformity is yet to be determined. The effect of the break of the infective stimulus is, however, unknown. It will be interesting to correlate the long-term results of this case with those of the other 2 cases involving surgical intervention for bronchiolitis in London and Zurich.

\section{References}

1. Messineo A, Fusaro F, Mognato G, et al. Lung volume reduction surgery in lieu of pneumonectomy in an infant with severe unilateral pulmonary interstitial emphysema. Pediatr Pulmonol. 2001;31:389-93.

2. Bloch KE, Weder W, Boeheler A, et al. Successful lung volume reduction in a child with severe airflow obstruction and hyperinflation due to constrictive bronchiolitis. Chest. 2002;122:747-50.

3. Cohen G, Saglani S, Dinwiddie R, et al. An alternative to lung transplantation. Pediatr Pulmonol. 2003;36:357-8.

4. Keller CA, Naunheim K, Osterloh J, et al. Histopathologic diagnosis made in lung tissue resected from patients with severe emphysema undergoing lung volume reduction surgery. Chest. 1997;111:941-7.

5. Duarte IG, Gal AA, Mansour KA, et al. Pathologic findings in lung volume reduction surgery. Chest. 1998;113:660-4. 